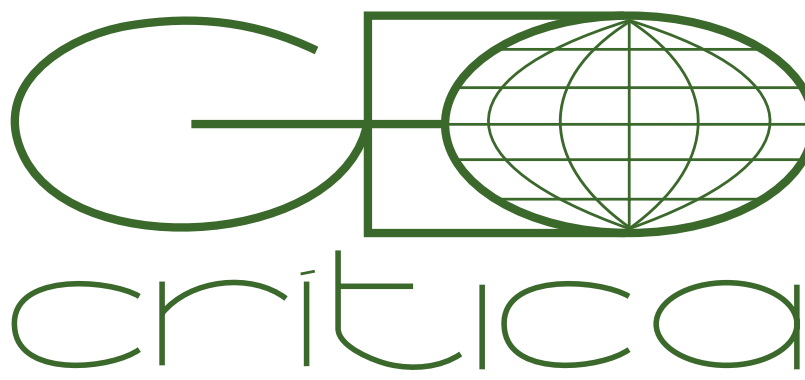

\section{Scripta Nova}

Revista Electrónica de Geografía y Ciencias Sociales Universitat de Barcelona

15 de octubre de 2019

\title{
LOS SIGNIFICADOS DEL TERRITORIO. ENSAYO INTERPRETATIVO DE LOS DISCURSOS SOBRE EL TERRITORIO DE MOVIMIENTOS SOCIALES EN COLOMBIA
}

\author{
Alice Beuf \\ Universidad Nacional de Colombia. \\ aabeuf@unal.edu.co
}

Recibido: 3 de julio de 2018; Devuelto para correcciones: 10 de noviembre de 2018; Aceptado: 28 de enero de 2019

Los significados del territorio. Ensayo interpretativo de los discursos sobre el territorio de movimientos sociales en Colombia (Resumen)

La polisemia del término territorio es alta en el debate académico y en los discursos de los movimientos sociales. En Latinoamérica y en Colombia en particular, el territorio se construyó como objeto de las reivindicaciones sociales que reclaman el "derecho al territorio" y que se oponen a la concepción hegemónica promovida por las políticas oficialistas de ordenamiento territorial. Se conforman resistencias territoriales, nuevas y antiguas, sobre la base de concepciones alternativas que tensionan el territorio estatal. En este artículo se realiza un rastreo del significado otorgado al territorio por parte de organizaciones sociales colombianas del ámbito local (urbanas, campesinas, indígenas, afrodescendientes) para entender la diversidad de prácticas y significados que surgen de las reapropiaciones locales del concepto de territorio.

Palabras clave: Territorio; territorialidades; derecho al territorio; movimientos sociales; Colombia

\section{The meanings of the territory. Interpretative essay of the speeches on the territory of social movements in Colombia (Abstract) \\ The polysemy of the territory is high in the academic debate and in the discourses of the social movements. In Latin America and Colombia in particular, the territory was built as an object of social demands that claim the "right to the territory" and that oppose the hegemonic conception of the territory promoted by the official policies of territorial ma- nagement. New and ancient territorial resistances are formed on the basis of alternative territorial conceptions, which stress the state territory. This article traces the significance of territory according to various local Colombian social organizations (urban, peasant, indigenous, Afro-descendant) to understand the diversity of practices and meanings that arise from the local reappropriation of the concept of territory.}

Key words: Territory; territorialities; right to the territory; social grassroots; Colombia 
Luego de la firma del Acuerdo de Paz en 2016 entre el gobierno y la guerrilla de las FARC, se ha observado en Colombia la efervescencia de un sinnúmero de discursos en torno al territorio, la promoción de programas y políticas "con enfoque territorial", todo ello en el marco de un debate nacional sobre la "paz territorial" ${ }^{1}$ al tiempo que se reconfiguran las correlaciones de fuerza en los espacios dejados por los excombatientes. La idea de "paz territorial" fue mencionada por primera vez en marzo 2013 por Sergio Jaramillo, en ese tiempo Alto Comisionado por la Paz, en una conferencia en la Universidad de Harvard. Allí, definió la construcción de la paz territorial como la necesaria imposición de: "una lógica de inclusión e integración territorial, basada en una nueva alianza entre el Estado y las comunidades para construir conjuntamente institucionalidad en el territorio. "Institucionalidad" entendida nuevamente no sólo como la presencia de unas entidades estatales, sino como el establecimiento conjunto de unas prácticas y normas que regulen la vida pública y produzcan bienestar" ${ }^{\prime 2}$. En esta perspectiva, la promoción de la paz territorial se entiende ante todo como el reconocimiento y la garantía de la pluralidad de usos y apropiaciones del territorio y su posible convivencia con la soberanía estatal, en el marco del Estado social de derecho definido por la Constitución política de 1991 en su artículo 1.

El discurso oficial presenta así la discusión sobre el significado del territorio para todos los actores. En efecto, de manera paradójica o más bien por falta de coherencia entre las instancias de gobierno, desde la perspectiva oficialista se sigue refiriendo al territorio como algo único, como una porción del espacio geográfico. Esta concepción reduccionista según la cual el territorio se asemeja al espacio físico que soporta las actividades humanas y que tiene que ser ordenado en función de metas desarrollistas, sigue siendo dominante en las instancias gubernamentales, y sobre todo en las políticas de ordenamiento territorial. La visión hegemónica e instrumental del territorio (el territorio como instrumento de dominación al servicio del desarrollo) oculta la dimensión conflictiva del mismo, inherente a su carácter multiescalar y multidimensional ${ }^{3}$. Desconoce los trabajos de los geógrafos que con contundencia mostraron cómo, en el espacio geográfico, existen múltiples territorios, esto es, "espacios apropiados, espacios hechos cosa propia e instituidos por sujetos y grupos sociales que se afirman por medio de él" ${ }^{\prime 4}$. La conflictividad del territorio no se debe entender como la existencia de disputas por el control del territorio sino más bien como la dinámica propia de la multiterritorialidad que configura el espacio geográfico ${ }^{5}$. Los grupos y sujetos sociales habitan, se apropian y valoran de manera singular sus territorios, y cada uno de estos territorios tiene un sentido particular para estos grupos y sujetos. De ahí, la asombrosa riqueza semántica de la noción que refleja la pluralidad de concepciones y usos sociales y políticos de los territorios.

\footnotetext{
1 Cairo et al., 2018.

2 Jaramillo, 2013.

3 Fernandes 2009, p.6.

4 Porto-Gonzalves 2009, p.13.

5 Haesbaert, 2013.
} 
Para ahondar en la comprensión de la naturaleza del territorio y aportar en la reflexión sobre el alcance de las políticas de ordenamiento territorial, proponemos en este artículo realizar un análisis de la manera en que se entiende el territorio en los discursos de los movimientos sociales, con base en el caso colombiano. Lejos de ser un término neutro, el territorio adquirió en las últimas décadas una importante dimensión de lucha y resistencia política ${ }^{6}$ a la vez que se incrementó su uso en el discurso oficial. Existe allí una gran tensión entre dos grandes tipos de territorialidad, que podríamos caracterizar en un primer momento como la estatal y la popular, cada una relacionada con formas muy distintas de entender lo que es el territorio. Con tal propósito, se trató de analizar las interpretaciones y conceptualizaciones que los movimientos sociales construyen alrededor del territorio, de su territorio. En ese sentido, no nos interesa tanto la manera cómo conocen su territorio ${ }^{7}$, sino cómo entienden lo que es territorio y cómo movilizan esta noción en sus registros de luchas. Así, realizamos un rastreo del significado del territorio para las organizaciones sociales colombianas que tienen reivindicaciones de carácter territorial. Es importante tener en mente que las reivindicaciones territoriales de estos movimientos sociales son el resultado de complejos procesos históricos, no obstante la presente investigación no alcanza a estudiar la evolución semántica de las representaciones acerca del territorio en la larga duración.

El presente artículo inicia con la discusión teórica sobre las territorialidades alternativas en Latinoamérica, luego describe el material recolectado, producido por unas 22 organizaciones sociales colombianas, y finalmente, desarrolla un análisis de discursos para identificar los principales significados del territorio para los movimientos sociales estudiados.

\section{El giro de los estudios sobre el territorio y su importancia en América latina}

Hasta aproximadamente los años 1980, dominaban concepciones del territorio influenciadas por la perspectiva ratzeliana ${ }^{8}$ y/o centradas en la caracterización del territorio llamado westfaliano, es decir, el territorio del Estado moderno cuya territorialidad se define en términos jurídicos por el ejercicio de una soberanía exclusiva al interior de fronteras lineales 9 . Tales enfoques políticos se complementaron a partir de la mitad del siglo pasado con perspectivas económicas funcionalistas que realzaban las vocaciones de los territorios - sus ventajas comparativas-, con el propósito

6 Vacaflores, 2009; Silva Prado, 2016.

7 Collignon, 1996.

8 Ratzel, 1898-1899. Ratzel elaboró uno de los primeros trabajos de geografía política en su famoso artículo "Le sol, la société, l'Etat" donde define el suelo o territorio del Estado bajo una perspectiva organicista como sustento y soporte para la grandeza de los Estados, lo cual lo lleva a plantear la noción de lebensraum, el espacio vital.

9 Este tipo de territorio definido como el espacio circunscrito por fronteras lineales donde se ejerce la soberanía exclusiva del Estado resulta de un proceso histórico de invención política que remonta al tratado de paz de Westafalia en 1648 que puso fin a la guerra de Treinte años en Alemania (Alliès, 1980). 
de definir un orden territorial eficiente, él que debía promover el ordenamiento territorial en ese tiempo en proceso de auge o de consolidación dependiendo de los países.

Estas concepciones evolucionaron a raíz de cambios teóricos profundos ocurridos en los años 1970-1980 en la manera de entender, por un lado, el espacio geográfico y por otro lado, el poder. El proceso de renovación teórica de la geografía emprendida desde los años $1970^{10}$ se sustentó en un cambio profundo de la concepción del espacio geográfico, de un espacio contenedor a un espacio relacional pensado como una dimensión de la dinámica social ${ }^{11}$. Además, los trabajos pioneros de Gottmann mostraron como las sociedades humanas necesitan compartimentar el espacio tanto para su uso económico como para la afirmación de su identidad como grupo, lo que determina el equilibrio entre encerramiento - iconografía - y apertura - circulación - de las construcciones territoriales ${ }^{12}$. De ahí, se desprendieron nuevas teorizaciones del territorio en tanto éste se concibe como "una construcción a partir del espacio geográfico"13 y de la territorialidad pensada como sistema de relaciones dinámico y complejo que los individuos y grupos construyen con los territorios.

En ese contexto, aproximadamente a partir de los años 1980, la geografía crítica evidenció una crisis de la noción de territorio en tanto espacio controlado y organizado por "el" poder ${ }^{14}$. Tanto en su versión política (el territorio westfaliano del Estado moderno) como en su versión económica (los territorios usados por los agentes capitalistas hegemónicos), el territorio pensado desde lógicas espaciales dominantes se empezó a presentar como agrietado debido al reconocimiento de otras formas de territorialidades. Este cambio de enfoque le debió mucho a los trabajos de Michel Foucault. Al enfatizar el territorio no como un pedazo de la superficie terrestre sino como una categoría política en tanto está conformada por una población específica y al pensar el poder no como un objeto que se toma sino como relaciones de fuerzas que existen en todas partes, Foucault posibilitó el pensamiento de una pluralidad de territorialidades en tensión ${ }^{15}$. La concepción relacional foucaultiana del poder influenció profundamente a Claude Raffestin quien redefinió el objeto de la geografía política en el sentido de la identificación de las relaciones de poder entre los actores del territorio ${ }^{16}$. Para Raffestin, el territorio puede ser considerado como "el espacio informado por la semiosfera, es decir el conjunto de los signos; todos los mecanismos de traducción que son empleados en nuestras relaciones con la exterioridad pertenecen a la estructura de la semiosfera. [...] Las arreglos territoriales constituyen una semiotización del espacio, espacio paulatinamente traducido y transformado en territorio"17. Asimismo, la geografía crítica también se nutrió de los estudios com-

10 Santos, 1978.

11 Lévy y Lussault 2013, p.354.

12 Gottmann, 1973.

13 Fernandes, 2009, p.39.

14 Saquet, 2013; Girault, 2008.

15 Foucault, 2004; Elden, 2010, p.810.

16 Raffestin, 1980.

17 Raffestin, 1986. 
portamentales y etológicos para entender el territorio como resultado de las estrategias de control necesarias a la vida social ${ }^{18}$, lo que permitió plantear la posibilidad del ejercicio de la territorialidad en todas las escalas, desde los espacios domésticos hasta los Estados nacionales y los territorios transnacionales. Otro aporte importante fue él de Milton Santos, quien resaltó la tensión entre dos tipos de racionalidades en la organización del espacio geográfico: las llamadas "verticalidades" y "horizontalidades". Para este autor, las verticalidades se refieren a lógicas reticulares y jerárquicas de organización del espacio, que articulan los lugares de mando de la economía global con diferentes lugares o espacios dotados de alguna funcionalidad en el orden espacial hegemónico, mediante relaciones de dominación de los primeros hacia los segundos. En cambio, las horizontalidades son regidas por la copresencia en espacios continuos y conformadas por el conjunto de relaciones de proximidad que se tejen a escala local y regional ${ }^{19}$. Precisando su teoría, Santos propone al final de su vida la categoría de "territorio usado" para afirmar la imposibilidad de explicar el territorio sin su uso, por todos los actores y no solamente los Estados. El territorio usado es "un cuadro de vida, híbrido de materialidad y de vida social [...] es el territorio hecho y el territorio haciéndose, con técnicas, normas y acciones" ${ }^{\prime 20}$. Se aproxima también al concepto de bioespacio, en tanto "respuestas a procesos locales y regionales de desarrollo social, económico y político que vinculan actividades vitales de producción y reproducción con los recintos en que se ejecutan y de donde derivan elementos de continuidad social y diversidad cultural"21. Para Fals Borda, la categoría foucaultiana de bioespacio se opondría a la de las tecnoregiones, pensadas en el registro del espacio concebido lefevriano ${ }^{22}$, como divisiones del espacio que solo tienen sentido desde el pensamiento planificador, economicista, técnico, frío y externo a las realidades vividas por quienes allí habitan.

Sobre la base de tales aportes teóricos, varios autores empezaron a identificar la formación de "nuevas territorialidades", "territorialidades contra-hegemónicas" u "otras territorialidades", cuyo punto en común radica en la consolidación y visibilización de nuevas instancias de territorialidad, ya no dominantes (el Estado, las firmas multinacionales) sino dominadas, subalternas, y que tienen diferentes capacidades de apropiarse, controlar y/o defender un espacio común bajo lógicas propias. En el contexto actual, las "otras territorialidades" son el producto de formas de habitar el territorio, de usarlo y compartimentarlo de acuerdo con prácticas populares preexistentes a los usos capitalistas del territorio y que entran en conflicto con las territorialidades estatales y empresariales ${ }^{23}$. Pueden tratarse de territorialidades campesinas, indígenas, afrodescendientes, ecológicas, etc. Según los lugares, la relación a la territorialidad estatal presenta diversas configuraciones. Si existe en

18 Sack, 1986.

19 Santos, 2000, p.286.

20 Silveira, 2008.

21 Fals Borda, 2000.

22 Lefebvre, 1974.

23 Cataia, 2008. 
un mismo lugar una intersección de fuentes de autoridad territorial, las territorialidades alternativas pueden constituir "territorialidades superpuestas" y ser claramente desafiantes entre sí o frente al orden estatal, en el caso de establecerse sobre la base de soberanías de hecho. Por ejemplo, las zonas de retaguardia de la guerrilla de las FARC en la época de los diálogos del Caguán constituyó un caso emblemático de territorialidad superpuesta ${ }^{24}$. Pero también pueden expresar otros modos de habitar y apropiarse del territorio, diferentes a los de las territorialidades dominantes, pero que no cuestionan el Estado ni el modelo de desarrollo económico hasta sus fundamentos políticos. Igualmente, las tensiones no necesariamente existen entre territorialidades estatales y territorialidades contra-hegemónicas pero pueden manifestarse entre diferentes tipos de territorialidades no-estatales (caso por ejemplo de los territorios controlados por grupos paramilitares frente a los cuales se pueden oponer diversos tipos de territorialidades alternativas). De tal manera, debemos reconocer la gran diversidad de análisis y enfoques que remiten a un conjunto de procesos de naturaleza y origen muy diferentes.

Sin embargo, en América latina, prevalecen los enfoques postcoloniales para explicar el choque entre dos concepciones del territorio: la primera, conservadora, heredada del colonialismo, soportada por la organización político-administrativa de los Estados nacionales y según la cual el territorio no es algo para los beneficios de la población sino que funciona bajo lógicas enajenantes; la segunda, arraigada a los territorios originarios (desarticulados por los colonizadores) y asociada a los movimientos de resistencia frente a la avanzada espacial del capitalismo global ${ }^{25}$. Estas otras territorialidades se construyen cada vez más como verdaderas reivindicaciones basadas en el clamor por el derecho al territorio, es decir, por el territorio definido de manera propia, tanto en lo relacionado al territorio-abrigo base de la reproducción social del grupo como al territorio-recurso para la organización y acción política. Por ejemplo, las luchas campesinas ya no giran en torno a demandas por la tierra sino a demandas por el territorio, dándole a este último un significado eminentemente político.

Afirmar que los campesinos solo reclaman para sí tierras es designarlos como meros actores económicos, imposibilitados para ser actores políticos legítimos. Hoy se ve claramente cómo la tierra no es el territorio y cómo la diferencia consiste en el tránsito que hay entre la dimensión económica de producción de la riqueza hacia la dimensión política de la organización de la vida social y la tramitación de la conflictividad. Estas comunidades han venido explicitando en las últimas décadas el reclamo de lo territorial como derecho a la autodeterminación frente a un Estado y a unas elites que han tenido el monopolio de la definición de los espacios sociales internos y externos, y de las funciones y lugares a ocupar dentro de ellos, bajo la idea capitalista del territorio. ${ }^{26}$

Estas discusiones tienen particular relevancia en la geografía y la antropología latinoamericanas, desde hace un poco más de una década. También desde los estu-

24 Agnew \& Oslender, 2010, p.201.

25 Vacaflores y Lizárraga, 2009.

26 Silva Prada, 2016. 
dios históricos, se ha investigado la presencia de territorialidades alternativas desde el periodo colonial y se ha analizado su rol en los procesos de ordenamiento y control territorial orquestado desde el poder central ${ }^{27}$. La mayoría de las investigaciones proceden del estudio de un cierto tipo de población: estudios indigenistas, estudios rurales, etc. Pocos son los trabajos que intentan sistematizar estas problemáticas abarcando una diversidad de tipos de racionalidades y de territorialidades asociadas.

Los estudios sobre pueblos indígenas hacen énfasis en que las reivindicaciones territoriales son constitutivas de las movilizaciones indígenas, ello en razón de los despojos coloniales de los cuales fueron víctimas. Sin embargo, en los años 19902000, el contexto de reconocimiento del carácter multiétnico, multicultural o plurinacional, abierto por los nuevos constitucionalismos en el subcontinente, permitió ampliar el alcance de estas reivindicaciones. El reconocimiento de los pueblos indígenas como sujetos con derechos específicos, que no poseen el resto de las poblaciones nacionales porque son de naturaleza colectiva, incluyó el reconocimiento de formas específicas de territorialidad, enmarcadas en la historia de los pueblos aborígenes, al igual que para las comunidades afro descendientes.

Con grados y formas diferentes de autonomía territorial según los países latinoamericanos ${ }^{28}$, estas otras territorialidades fueron oficialmente reconocidas e integradas a las herramientas del Estado nacional moderno: otorgamiento de derechos colectivos sobre las tierras (titulación de tierras) y reorganización de los límites político-administrativos (municipios) bajo distintas figuras establecidas en las Constituciones (resguardos indígenas, entidades territoriales indígenas, tierras indígenas, etc.). Si bien la identidad de cualquier grupo social no puede prescindir de su territorialidad, en el caso de los pueblos indígenas esta asociación parece aún más fuerte en la medida que las construcciones históricas del vínculo con el territorio se dieron bajo lógicas radicalmente otras respecto a las lógicas occidentales que les fueron impuestas.

Los territorios no siempre remiten a un área delimitada; existe una gran forma de apropiaciones territoriales incluyendo por ejemplo territorios circulatorios en el caso de comunidades nómadas y territorios reticulares que articulan diferentes espacios con diferentes usos en diversos pisos bioclimáticos ${ }^{29}$. Por lo tanto, lo que es territorio para los pueblos indígenas, en sus culturas, sus cosmovisiones, encaja difícilmente en un perímetro delimitado por el Estado ${ }^{30}$. Las tensiones son aún mayores cuando estos territorios ad hoc, fruto de un acuerdo estatal, son constantemente amenazados por las incursiones de diversos actores, legales e ilegales.

La existencia de derechos territoriales constituye un motivo para las movilizaciones indígenas en caso de ser desconocidos o vulnerados ${ }^{31}$, pero también permi-

27 Herrera, 2002.

28 González, 2010.

29 Martínez Zamora, 2010.

30 Serje, 2017.

31 Surallés, 2009. 
ten avanzar hacia nuevas demandas de autonomías territoriales, cuestionando de manera más radical aún la soberanía estatal. En el marco de un conjunto de "relaciones, negociaciones, confrontación y participación que [los pueblos indígenas] tienen que establecer con el Estado y diversos actores locales, nacionales y transnacionales", se reconfiguran conceptualmente y de hecho las fronteras y el significado del territorio, a la vez que la autonomía indígena se construye de manera relacional ${ }^{32}$. El llamado al territorio se entiende como una estrategia que se puede movilizar de diferentes maneras según las correlaciones de fuerza de cada lugar y cada momento.

Los movimientos sociales campesinos jugaron también un papel muy importante en varios países latinoamericanos en la medida en que sus demandas de reconocimiento, para seguir existiendo y para llevar a cabo sus prácticas sociales y territoriales, se transformaron en demandas de nuevos tipos de autonomías territoriales que ampliaron las modalidades de legitimación para la constitución de nuevos territorios.

Es el caso de las Zonas de Reserva Campesina (ZRC) en Colombia que constituyen una nueva figura jurídica contemplada en la ley desde 1994 pero que sigue siendo contestada por importantes sectores políticos en el poder ${ }^{33}$. La expansión de los agronegocios, que reconfiguran regiones enteras mediante reajustes de las morfologías rurales y conformación de grandes extensiones de tierras para monocultivos, dieron lugar a movimientos de resistencia articulados en torno a la defensa de "territorios campesinos". Para geógrafos brasileños, se trataría de la disputa entre tipos de territorios, asociados a diferentes intencionalidades que otorgan significados radicalmente diferentes al territorio al punto que no pueden coexistir, lo que, en este caso, cuestiona la posibilidad efectiva de la multiterritorialidad.

\begin{abstract}
Una clase social no se realiza en el territorio de otra. Por esta razón, los territorios del agronegocio y de los campesinos y de los indígenas son diferentes, se organizan de diferentes formas, a partir de diferentes relaciones sociales. Así, mientras el agronegocio lo hace para la producción de mercancías, los grupos de campesinos lo hacen, primero, para su existencia, para desarrollar las dimensiones de la vida. [...] En estos territorios, tenemos diferentes formas de organización del espacio y del trabajo. Tenemos por tanto, dos relaciones sociales que producen dos territorios distintos y para expandirse, precisan destruirse uno a otro. Por tanto, el territorio capitalista se territorializa destruyendo territorios campesinos o indígenas, o se apropia de otros territorios del Estado. Los territorios campesinos se territorializan destruyendo el del capital, o el indígena o apropiándose de otros del Estado. En cuanto la frontera agrícola permanezca abierta este proceso continuará. Con el cierre de la frontera agrícola el enfrentamiento entre los territorios campesinos y el del capital será más intenso ${ }^{34}$.
\end{abstract}

Tales procesos de desterritorialización de las comunidades campesinas no se deben confundir con la desterritorialización muy a menudo asociada con la movilidad generalizada promocionada por la globalización: esta última sería una desterritorialización escogida y vivida de manera positiva. En cambio, la desterritorialización entendida como despojo puede llevar a la precarización territorial de los grupos

32 Ulloa, 2010.

33 Fajardo, 2012.

34 Fernandes, 2009. 
expulsados de sus tierras, campesinos, pero también pescadores, mineros, urbanos u otros, cuando no tienen los capitales económicos, políticos ni sociales para reconstruir su territorialidad individual y/o colectiva en otra parte ${ }^{35}$. Desplazar poblaciones de manera forzada, es decir violenta, o incluso mediante instrumentos del mercado es destruir territorios en el sentido que los mismos son maneras colectivas de habitar y relacionarse con la Tierra, más allá de las configuraciones materiales del espacio físico. Asimismo, las demandas acerca de la conformación, la invención y la defensa de los territorios campesinos se deben interpretar como procesos de reterritorialización mediante la lucha organizada en y por el territorio. Tal sería el caso de la Asociación Campesina del Valle del río Cimitarra (ACVC) que se conformó en la frontera agrícola como una posibilidad de reasentamiento para los campesinos desplazados de la región del Magdaleno Medio donde predominan hoy en día los agronegocios de palma africana. El reto es seguir existiendo como comunidad campesina al reconstruir allí formas campesinas de vivir y habitar la Tierra ${ }^{36}$.

Los debates sobre territorialidades alternativas en las ciencias sociales latinoamericanas abarcan entonces una multitud de procesos en las sociedades latinoamericanas. Carlos Walter Porto Gonçalves destaca dos niveles de análisis. El primero es él de la construcción histórica de territorialidades otras, sobre la base de una matriz de racionalidad propia de los grupos considerados. En el caso de la investigación de este autor, se trata de los seringueiros del Estado de Acre (Brasil) cuya territorialidad se caracteriza por el uso común de los recursos naturales (la selva amazónica), prescindiendo de la propiedad en tanto derecho formalizado, y por lo tanto del Estado como mediador. El segundo nivel de análisis es él de las innovaciones en el campo del derecho, a partir de las luchas por el reconocimiento de las territorialidades alternativas.

Así, gracias a un movimiento social políticamente organizado, las prácticas y saberes seringueros fueron oficialmente reconocidos "como un factor esencial para el establecimiento de un espacio territorial, en este caso una unidad de conservación ambiental". Se constituyó la nueva figura jurídica de las "reservas extractivistas" como territorio de "poblaciones extractivistas", porque estos grupos saben conciliar explotación de la naturaleza y conservación, lo que les otorgó una legitimidad especial que permitió salvar sus territorialidades ancestrales ${ }^{37}$. El reconocimiento de territorialidades otras replantea los fundamentos de la territorialidad estatal, por la posibilidad de reconfiguración de los mapas políticos nacionales, lograda mediante movilizaciones sociales y políticas.

Las discusiones teóricas sobre las territorialidades alternativas amplían las conceptualizaciones acerca del territorio y se articulan con procesos socio-políticos concretos y demandas sociales cada vez más fuertes. La lucha por la defensa del territorio se ha vuelto hoy en día un común denominador de muchos procesos sociales,

35 Haesbaert, 2011, p.40.

36 Hurtatis Espinosa, 2012, p.36.

37 Porto-Gonzalves, 2001. 
más allá de los solos movimientos indígenas y campesinos. En particular, el lema actual del derecho al territorio impulsa convergencias entre los movimientos urbanos y rurales: profundiza el sentido del derecho a la ciudad lefebvriano ${ }^{38}$ y suplanta las reivindicaciones para el acceso a la tierra que prevalecieron en los años 1970-1990. De ahí, se evidencia el potencial movilizador del término, que si bien se sintoniza con las aspiraciones y sensibilidades de nuestro momento histórico, puede sin embargo diluirse en un conglomerado de significados más o menos bien identificados, lo que obstaculiza que estas reivindicaciones sean escuchadas a la hora de diseñar y elaborar políticas de ordenamiento territorial. Por consiguiente, es preciso revisar cuidadosamente lo que significa el territorio para los movimientos sociales.

\section{Constitución de un corpus de materiales producidos por movimien- tos sociales con reivindicaciones territoriales}

Dentro de la gran nebulosa de los movimientos sociales colombianos, seleccioné unas 22 organizaciones y conformé un corpus de documentos producidos por las mismas. Como aproximación a las reivindicaciones territoriales que se expresan en la actualidad, este corpus de materiales responde a la búsqueda de una cierta representatividad en cuanto a los tipos de movilización (reivindicaciones de carácter ambientalista, indígena y afrodescendiente, campesino y urbano) y en cuanto al ámbito geográfico de expresión de los movimientos sociales, intentando cubrir buena parte de las regiones del país. Es preciso subrayar aquí que, si bien se optó por definir un "carácter" de las reivindicaciones dependiendo de la naturaleza de las organizaciones que las expresan, la mayor parte de estas resultan de la confluencia de varios intereses y tipos de racionalidades, como por ejemplo campesina y ambiental, campesina e indígena, ambiental y urbana, etc. Este conjunto de materiales constituye la base sobre la cual se realizó un análisis de discursos que tuvo como objetivo evidenciar los diferentes significados del territorio elaborados por los movimientos sociales. El cuadro l presenta y describe las organizaciones sociales seleccionadas y los materiales que se utilizan en el análisis posterior.

Al respecto, es necesario trazar algunas observaciones sobre la conformación del corpus de documentos. Debido a las limitaciones materiales de la investigación y la imposibilidad de financiar la cantidad requerida de salidas de campo, se optó por realizar la revisión documental en la web, lo que permitió reunir materiales variados, pero introdujo sesgos en el análisis. Las organizaciones sociales seleccionadas presentan un cierto grado de visibilidad, benefician o se beneficiaron en su mayoría de distintos tipos de apoyos para consolidar su comunicación. Son las que vemos y que escuchamos. Por ejemplo, varias organizaciones seleccionadas o algunas de sus componentes recibieron premios a nivel nacional o internacional. Con la metodología escogida, no alcanzamos a tomar en cuenta las organizaciones que trabajan en el

38 Lefebvre, 1968. 
Cuadro 1 : Corpus de materiales producidos por movimientos sociales colombianos con reinvidicaciones territoriales.

\begin{tabular}{|c|c|c|c|}
\hline Nombre & Área geográfica & Presentación & $\begin{array}{l}\text { Materiales } \\
\text { recolectados }\end{array}$ \\
\hline
\end{tabular}

\section{Reivindicaciones territoriales de carácter ambientalista}

\begin{tabular}{llll}
\hline $\begin{array}{l}\text { l. Red Tejiendo Pára- } \\
\text { mos - Región Centro }\end{array}$ & $\begin{array}{l}\text { Regional. Cundinamarca } \\
\text { y Boyacá. }\end{array}$ & $\begin{array}{l}\text { Red creada en 2013 para la } \\
\text { defensa de los páramos y la } \\
\text { alta montaña. }\end{array}$ & $\begin{array}{l}\text { Memorias de asam- } \\
\text { bleas }(2013,2015) .\end{array}$ \\
$\begin{array}{l}\text { 2. Cinturón Occiden- } \\
\text { tal Ambiental (COA) }\end{array}$ & $\begin{array}{l}\text { Regional. Jardín, Cara- } \\
\text { manta, Valparaíso, Tá- } \\
\text { mesis, Tarso, Pueblorico, } \\
\text { Jericó y Andes. }\end{array}$ & $\begin{array}{l}\text { Red creada en 2011 en con- } \\
\text { tra-respuesta al denominado } \\
\text { Cinturón del Oro del Suroeste } \\
\text { antioqueño. }\end{array}$ & $\begin{array}{l}\text { Comunicados a la } \\
\text { opinión pública (2014- }\end{array}$ \\
\hline
\end{tabular}

3. Colectivo por la Protección de la Provincia de Sugamuxi

Local. Provincia de Sugamuxi (Boyacá).

4. Movimiento Regio- Regional (Santander, nal por la Defensa del Antioquia, Huila) pero de Territorio y la Vida ¡Rios Vivos!

5. Movimiento social por la vida y la defen- queño. sa del territorio del oriente antioqueño (MOVETE)

6. Corporación Ambiental Caminando el Territorio

7. Comité Ambiental en Defensa de la Vida

Local. Soacha. alcance nacional.

Regional. Oriente antio-

Desde 2012, emprende acciones y movilizaciones en contra de los megaproyectos minero-energéticos.

Creada en 2011, agrupa los procesos organizados contra las represas Hidrosogamoso, Hidroituango, El Quimbo y otros proyectos.

Creado en 2013, agrupa diversas organizaciones populares y campesinas de corte ambiental.

Conformada en 2016, realiza educación y gestión ambiental para la apropiación social del territorio.

Local y Regional. Municipio de Cajamarca y Departamento del Tolima.
Desde el 2010 impulsa el movimiento ambiental en contra del proyecto minero la Colosa y otros.

proyecto comunicativo de denuncia y pedagogía, disputas ambientales (s.f.).

Artículos publicados en los blogs, denuncias públicas, comunicados (2011-2016).

Artículos publicados en el blog (2015).

Documentos de trabajo internos (s.f.).

Blog y comunicados públicos (2016-2017)

\section{Reivindicaciones territoriales de carácter indígena y afrodescendiente}

8. Asociación de Cabildos Indígenas del Norte del Cauca (ACIN)

9. Organización de los Pueblos Indígenas de la Amazonía Colombiana (OPIAC)

10. Consejo Territorial de Cabildos Indígenas (CTC) de la Sierra Nevada de Santa Marta
Local. Parte del Consejo Regional Indígena del Cauca (CRIC).

Regional (Amazonas, Caquetá, Guainía, Putumayo y Vaupés).
Creada en 1994, apoya la formulación de los planes de vida de las comunidades.

Creada en 1995, ejerce una representación política de los pueblos indígenas de la Amazonía.

Creado en 1999, en aras del Regional. Reúne las cuatro organizaciones indígenas de la Sierra Nevada de Santa Marta.
Declaraciones y comu nicados, Mandato de liberación de la Madre Tierra (2005).

Memorias de la II Cumbre Regional Amazónica (2013). Mandato de los pueblos indígenas de la Amazonía (2012). Notas Parque Natural Nacional Yaigojé Apaporis.

Pronunciamiento (2016), Posición frente a megaproyectos (2007), Visión ancestral del territorio (2006). 


\begin{tabular}{|c|c|c|c|}
\hline Nombre & Área geográfica & Presentación & $\begin{array}{l}\text { Materiales } \\
\text { recolectados }\end{array}$ \\
\hline
\end{tabular}

11. Organización

Nacional Indígena de

Colombia (ONIC)

12. Consejo Comunitario Mayor de la Organización Popular del Alto Atrato (COCOMOPOCA)
Nacional. Reúne 47 organizaciones zonales y regionales en 28 de los 32 departamentos del país.

Local. Municipios de Lloró, Bagadó, Atrato y Certegui (Chocó).
Creada en 1985 como fruto de las movilizaciones indígenas históricas, es la autoridad de gobierno y representación de los pueblos indígenas de Colombia.

Creado en 1994, reúne 43 organizaciones campesinas afrodescendientes para la defensa y gestión del territorio colectivo.
Mandato político general de los pueblos indígenas de Colombia (2012-2016).

Redes sociales, artículos, informes y documentos de acompañamiento (2014-2015).

\section{Reivindicaciones territoriales de carácter campesino}

13. Asociación Nacional de Zonas de Reserva Campesina (ANZORC)

14. Organización de Poblaciones Desplazadas Étnicas Campesinas (OPDs)

15. Asociación para el Desarrollo Campesino (ADC)

16. Asociación de Las Hermosas con Desarrollo Al Futuro (AsoHermosas).

17. Red de Comunidades e Iniciativas de Paz desde la Base

Nacional. Agrupa Zonas
de Reservas Campesinas
(ZRC) constituidas, de
hecho y en proceso.
hecho y en proceso.

Regional. Montes de María

Regional. Reúne familias de 8 municipios del Departamento de Nariño.

Local. Agrupa campesinos de las veredas del Cañón de Las Hermosas (Sur del Tolima).

Nacional. Coordina 30 iniciativas locales y regionales de paz.
Creada en 2000, reúne 66 asociaciones de ZRC para la paz, los derechos humanos, el acceso a la tierra y la soberanía alimentaria.

Coordinación de diversos procesos campesinos de los Montes de María, en defensa del Territorio y la identidad campesina, desde 2010.

Creada en 1980, apoya la construcción de actores sociales campesinos de la región.

Creada en 2007, esta organización comunitaria vela por las afectaciones de la represa del río Amoyá y el desarrollo rural.

Busca defender el estado social Blog, comunicados, de derecho y aportar a la cons- documento "La Tierra trucción de una cultura de paz. y el Territorio: la clave para la Paz en Colom-

bia" (2010).

Declaraciones políticas de Encuentros Nacionales de ZRC, declaración política de la Asamblea Nacional de ANZORC (2016).

Revista La Parcela informativa - Montes de María (2016) y otros documentos del blog

Documento de presen-

Plan de Desarrollo Sustentable corregimiento Las Hermosas (20152013) y cartillas. tación (s.f.).

\section{Reivindicaciones territoriales de carácter urbano}

18. Mesa Ambiental
de los Cerros Orien-
tales
$\begin{array}{ll}\text { 19. Cumbre Popular } & \text { Bogotá y su área metro- } \\ \text { Urbana } & \text { politana }\end{array}$

20. Foro Social Urbano Alternativo y Popular politana

Medellín y su área metropolitana. 


\begin{tabular}{llll}
\hline Nombre & Área geográfica & Presentación & $\begin{array}{l}\text { Materiales } \\
\text { recolectados }\end{array}$ \\
\hline $\begin{array}{l}\text { 21. Mesa Interbarrial } \\
\text { de Desconectados }\end{array}$ & $\begin{array}{l}\text { Medellín y el área metro- } \\
\text { politana del valle del río } \\
\text { Aburrá }\end{array}$ & $\begin{array}{l}\text { Desde 2009, articula organiza- } \\
\text { ciones comunitarias para ser- } \\
\text { vicios públicos domiciliarios y } \\
\text { vivienda digna. }\end{array}$ & $\begin{array}{l}\text { Artículos publicados en } \\
\text { el blog (2014-2016). }\end{array}$ \\
\hline Otras & & & \\
\hline $\begin{array}{l}\text { 22. Cumbre Agraria } \\
\text { Étnica y Popular }\end{array}$ & $\begin{array}{l}\text { Proceso organizativo na- } \\
\text { cional. Organizaciones } \\
\text { campesinas, indígenas } \\
\text { afrocolombianas. }\end{array}$ & $\begin{array}{l}\text { Creada en 2013, es un espa- } \\
\text { cio de organización popular, } \\
\text { conformado a raíz de los paros } \\
\text { regionales y el Paro Nacional } \\
\text { Agrario de 2013. }\end{array}$ & $\begin{array}{l}\text { Documento "Cumbre } \\
\text { Aguraria Étnica y Po- } \\
\text { demandas históricas y } \\
\text { contemporáneas". }\end{array}$ \\
\hline
\end{tabular}

Fuente: Elaboración propia

terreno y que no son articuladas de ninguna manera con procesos o redes de apoyo nacionales o internacionales. Por lo tanto este trabajo no pretende la exhaustividad en el abordaje de la noción de territorio, a diferencia de otros mucho más dispendiosos basados en el inventario de conflictos territoriales en ciertas regiones del país ${ }^{39}$ o a nivel global ${ }^{40}$.

Asimismo, el cuadro l permite apreciar la existencia de varias "generaciones" de organizaciones sociales. Un primer grupo, de marcado carácter identitario, se constituyó formalmente a mitad de los años 1990, en el marco de la implementación de la Constitución política de 1991, sobre la base de movimientos sociales que se venían organizando desde décadas atrás. Varias organizaciones de este grupo están asociadas con procesos formalizados de autonomías territoriales (resguardos indígenas, consejos comunitarios, zonas de reservas campesinas) y por lo tanto constituyen reconocidos casos de territorialidades alternativas, cada uno con su historia propia. Valga la pena aquí mencionar la historia específica del movimiento indígena colombiano que se origina en las luchas de Manuel Quintín Lame (1880-1967) que llevaron a la fundación del Consejo Regional Indígena del Cauca (CRIC) en 1971 y de la Organización Nacional Indígena de Colombia (ONIC) en 1982. Un segundo grupo de organizaciones, muy distintas, formalizadas en la década de los 2000, abarca sobre todo organizaciones ambientalistas y urbanas que no buscan el reconocimiento de figuras de autonomía territorial sino la construcción de modelos alternativos de ordenamiento territorial, al tiempo que realizan acciones de veeduría ciudadanas y de acompañamiento a comunidades afectadas, desterritorializadas o amenazadas por la expansión de las territorialidades estatales o del capital. Se trata así de territorialidades alternativas en el sentido del reconocimiento y defensa de la multiterritorialidad frente a la imposición, desde arriba y a menudo violenta, de las territorialidades dominantes en nombre de las políticas estatales y de ordenamiento territorial. La mayoría de estas organizaciones se consolidaron en los años 2014-2015, produciendo muchos de sus documentos en esos años. Desde entonces, su actividad comunicativa parece experimentar cierto retroceso. Como principales explicaciones a este

39 Observatorio Nacional de Paz, 2012.

40 Leah Temper y Martinez-Alier, 2015. 
fenómeno, debemos mencionar la reconfiguración de la financiación de la cooperación internacional en el marco del posconflicto, canalizada por el Estado y que ya no llega directamente a las organizaciones. Otro elemento muy importante por destacar es la nueva ola de asesinatos, violencias y amenazas en contra de los líderes sociales del país desde 2016. Entre la firma del Acuerdo en 2016 y el 27 de febrero de 2018, 282 lideres de organizaciones sociales fueron asesinados, entre los cuales hay 57 indígenas (3,45\% de la población) y 26 afro-descendientes. Organizaciones como el Movimiento Ríos Vivos estudiado a continuación fueron fuertemente golpeadas por el asesinato de varios de sus líderes.

\section{Lo qué es territorio para los movimientos sociales}

Para el tratamiento de este corpus de materiales, se asumió que la pregunta de investigación demandaba un método inductivo de análisis del discurso, que debía hacer surgir las categorías de análisis a medida que se avanzaba en la investigación. Debido a los usos a menudo genéricos, vagos o inadecuados del término territorio, se necesitó ir más allá de la identificación de las acepciones de cada alusión a la palabra, llegando incluso a reflexionar sobre los significados implícitos. Por tales razones, se prefirió no usar software tipo Atlas.ti sino realizar un análisis comprensivo de los textos a partir de su lectura directa.

\section{Territorio, tierra y Tierra Madre}

En su gran mayoría, los movimientos sociales afirman que el territorio es "algo más" que el espacio pensado como soporte de las actividades humanas. Dependiendo de los casos, es algo más que "el entorno", "el espacio natural", "la tierra" o incluso que "las fronteras y los límites". Es en los contextos urbanos donde se encuentran tal vez los significados más pobres del territorio, a veces asimilado a la "estructura ecológica principal", es decir, el espacio supuestamente natural de una ciudad, o al entorno regional. En otros casos, el territorio es un sinónimo estricto del territorio del municipio: aquí se observa una apropiación directa, una interiorización de las categorías territoriales del Estado a pesar de que se pueda elaborar un discurso crítico por otra parte. Así, la Corporación Ambiental Caminando el Territorio desarrolla un análisis bastante preciso de los impactos ambientales de la urbanización y la minería en Soacha, sin decir nada en lo absoluto de la cercanía de Bogotá: el territorio es un contenedor, con sus fronteras internas (los diferentes corregimientos) al interior del cual se tiene que llevar a cabo la movilización en pro de la sostenibilidad ambiental. En este caso predomina la visión ambiental, e incluso nostálgica de los paisajes naturales de "Suacha con U, de valles xerofíticos y humedales, de montañas besadas por la diosa niebla, gobernadas por frailejones y águilas, donde las aguas y en el algún momento el majestuoso río Suacha discurrían libres" (6). Se trata de un territorio donde la presencia humana no es necesaria y representa incluso una fuente de amenaza. 
No obstante, es mucho más compartida la idea que "tanto los individuos como las comunidades son sujetos que hacen parte del territorio" (17), y que por lo tanto este último remite a la relación entre la comunidad y la naturaleza e involucra dimensiones culturales, identitarias, e incluso patrimoniales. Por ejemplo, las comunidades afrodescendientes del Alto Atrato establecen una relación de identidad entre las personas y el río en torno al cual se nace, se vive y se muere. De ahí los rituales como las ombligadas de los recién nacidos o los bautismos en los ríos: "el afro solo se piensa en relación con su territorio" (12).

Allí avanzamos hacia un primer significado positivo: el territorio es un tejido de relaciones entre los hombres y la naturaleza, entre los miembros de una misma comunidad o de varias comunidades, entre sujetos o agentes sociales internos y externos. Estos territorios relacionales abarcan tanto los espacios de vida, de hábitat de un grupo, como los espacios donde se trabaja, por ejemplo en el caso de los proyectos productivos campesinos (4). El territorio es el espacio físico más "el patrimonio inmaterial que se desprende de las comunidades que lo han habitado o conservado, lo van cantando, lo han hecho parte de sus usos, costumbres leyendas, dichos" (17). Caminar, tejer, construir el territorio son imágenes bastante utilizadas. El territorio también puede tejer relaciones entre culturas, como en el caso de las experiencias de territorialidades interculturales $(9,22)$. Así se entiende también la dimensión histórica de este tejido de relaciones, construido a lo largo del tiempo, y que guarda la memoria de los acontecimientos y de los lugares transformados, a veces despojados, destruidos: "el territorio tiene memoria" (19). Estos tejidos de relaciones sin embargo pueden ser "desconocidos" o "ignorados" $(5,6)$ por los agentes hegemónicos que los rompen imponiendo sus megaproyectos. En el caso del Oriente antioqueño, se alerta sobre la repetición de los ciclos de violencia que fragilizan los procesos de retorno y no permiten la reconstrucción del territorio: "la imposición de estos conflictos [creación de hidroeléctricas] son una amenaza para la reconstrucción del tejido social y la reconciliación en los territorios" (6). El desplazamiento forzado no es solo traumático a nivel individual, representa también la destrucción de los territorios en tanto tejidos de relaciones sociales, económicas, culturales y políticas construidos a lo largo del tiempo. Es el fin de la existencia como comunidad anclada en el territorio.

Este tejido de relaciones que es el territorio tiene una dimensión existencial en la mayoría de los documentos consultados. Al respecto, hay que resaltar su importancia como garante de la "dignidad", o de la "vida digna". La relación con el territorio es entonces un elemento primordial de nuestra humanidad sin el cual estaríamos amputados, privados de una parte de nuestro ser. De tal manera adquiere una dimensión verdaderamente ontológica. Otro significado muy presente, con diversos matices según el carácter del enunciador, es él que afirma que el territorio es vida. En un primer nivel, el territorio es vida porque permite la existencia y sobrevivencia de la comunidad en la medida en que brinda recursos naturales esenciales (agua y alimentos) y seguridad. Es el territorio-abrigo mencionado en muchos textos teóri- 
cos. Encontramos en el corpus diversas versiones de ello, incluso la idea del cuerpo como primer territorio que defienden mujeres víctimas del conflicto armado (17). Igualmente, las numerosas referencias a la soberanía y seguridad alimentaria se tienen que interpretar en ese sentido. En un segundo nivel, el territorio es vida porque permite la sobrevivencia de todos los animales, las plantas y la Humanidad en general. Para los ambientalistas y campesinos, el territorio es fundamental para el mantenimiento del equilibrio ecológico necesario para la vida de todos los seres del planeta. Para el Comité Ambiental de Defensa de la Vida, "no es un problema exclusivo del Tolima sino de Colombia y el mundo; se trata de la defensa del planeta", lo que lleva a proyectar el movimiento en redes de "solidaridad internacionalista" (7).

Sin embargo, para los movimientos indígenas, el territorio es vida por algo más: porque es a la vez la Madre Tierra, que nos ha dado todo. "El territorio es nuestra casa, nuestra Madre, nuestra obligación" (8). Aquí, encontramos una dimensión moral del territorio, ya que luchar por la Madre Tierra es un mandato ancestral de los pueblos indígenas. Los indígenas del Norte del Cauca afirman orgullosamente que "desde este rincón del planeta, hacemos lo que nos corresponde por la Tierra y la vida" (8). Es allí que se puede entender la actualidad del movimiento de liberación de la Madre Tierra, sometida porque tiene dueños. Es vital para estas comunidades indígenas recuperar tierras para "desalambrar la Tierra", sembrarla y así liberarla. Para los pueblos indígenas de la Sierra Nevada de Santa Marta, la responsabilidad de proteger el territorio para los demás es aún más fuerte puesto que el territorio ancestral constituye un referente vigente, con base en el cual se determinan los roles de los cuatros pueblos de la Sierra hacia los hermanos menores, es decir, los mestizos que actúan de manera irresponsable en nombre del supuesto desarrollo, devastador de la naturaleza.

“Todas las cosas y manifestaciones que existen en el Universo están en nuestro territorio representadas en forma de tumas y piedras y a través de ellos se mantiene la comunicación y desde aquí tenemos la misión de mantener el equilibrio del mundo de manera espiritual, por eso la Sierra es el Corazón del mundo" (10).

El territorio ancestral es un "código" que solo pueden descifrar los chamanes al realizar rituales en los sitios sagrados. Son los sitios sagrados, articulados en red a partir por ejemplo del agua, los que dan las orientaciones para el manejo del territorio, porque en estos sitios se tienen las normas que indican como velar por el territorio (10). Asimismo, el territorio adquiere otra dimensión para los pueblos indígenas: la de un espacio sagrado. Si el ser de la Sierra es materialidad y espiritualidad (10), los demás pueblos indígenas también conciben el territorio como habitado por los espíritus de las aguas y de las plantas, como por ejemplo los Jaís del Suroccidente antioqueño (2). En ese sentido, cualquier intervención humana en el territorio puede generar un gran desequilibrio de la vida, tanto material como espiritual, y por eso, se recurre a rituales de pagamentos para pedir permiso y retribuir los daños causados en ambos niveles. 


\section{El territorio es un espacio de disputas}

Si bien la concepción oficialista borra la conflictividad inherente al territorio, esta dimensión es omnipresente en los textos producidos por los movimientos sociales. Casi siempre, se menciona que el territorio está amenazado, y que por lo tanto, hay que defenderlo. El lema de la defensa del territorio se ha generalizado a todos los tipos de movimientos sociales, urbanos, ambientales, campesinos o étnicos. Lo que está amenazado en particular son las dimensiones ambiental y social del territorio, su vocación agrícola en los contextos rurales y su carácter popular en los ámbitos urbanos: estas dimensiones son presentadas como desconocidas, ignoradas o meramente despreciadas.

La principal fuente de amenaza, por encima del conflicto armado, remite a la realización de megaproyectos, asociados al extractivismo en los espacios rurales y al urbanismo neoliberal en los contextos urbanos. En todos los casos, se tiene la representación de una territorialidad totalmente ajena al lugar, impuesta desde arriba y que tiene grados diferenciales de destrucción del territorio según su irreversibilidad o no. Algunos textos mencionan los impactos o los conflictos generados por los proyectos mientras que otros hablan de su carácter depredador, destructor, expulsor, excluyente o invasor. Las represas hidroeléctricas como El Quimbo o Hidrosogamoso constituyen los ejemplos más acabados de destrucción de los territorios, en todas sus dimensiones, con medidas de mitigación social y ambiental que no pueden compensar en lo absoluto los daños causados (4).

La crisis de la represa de Hidroituango que inició en mayo de 2018 y cuyo riesgo de rompimiento representa una amenaza directa para alrededor de 100000 personas que viven aguas abajo, resulta emblemática de las lógicas de destrucción ambiental, social y de la memoria de las comunidades afectadas, en este caso por los asesinatos en varios momentos históricos que rodean la historia del proyecto desde 1959 y por la sumersión de las fosas comunes donde fueron exhumados las víctimas de los grupos paramilitares de la región. Para algunas organizaciones, los megaproyectos promueven el exterminio del territorio y de las comunidades, para otros, desconocen el orden popular, lo invisibilizan, y luego lo destruyen. Es llamativo el conflicto respecto al alcance y significado de las declaratorias de "utilidad pública" que están asociadas a la mayoría de los megaproyectos y legitiman las expulsiones: "la preservación y el manejo de los recursos naturales renovables también son de utilidad pública" (5).

En algunos casos sin embargo, las amenazas vienen de la incursión de actores ilegales, como en el Alto Atrato azotado desde 2005 por la minería ilegal mecanizada en un contexto de confrontación armada. Las acciones de los grupos armados y la entrada de terceros dedicados a actividades extractivas ha provocado procesos de abandono del territorio: los miembros de COCOMOPOCA imputan al Estado la responsabilidad de esta catástrofe ambiental y social en la medida en que la titulación colectiva del territorio tardó más de 12 años, lo que debilitó la autoridad y 
autonomía de la organización para ejercer el control territorial y vigilar la entrada de actores externos (12).

En algunos casos, el territorio ya se encuentra destruido y se construyen relatos para mantener el vínculo territorial. Así lo proclaman los indígenas del Norte del Cauca quienes fueron despojados hace décadas de sus mejores tierras en las partes planas del Valle del Cauca y que tuvieron que huir hacia las vertientes empinadas de la cordillera central donde los suelos no son tan productivos. Allá cuidan los nacederos de agua mientras que abajo los ingenios azucareros y los complejos industriales la despilfarran y no reconocen que son dependientes de las acciones conservacionistas realizadas por los pueblos indígenas (8).

A veces, los territorios no son destruidos aún, pero la amenaza es tan fuerte que se busca "blindar los territorios", en general mediante estrategias conservacionistas y su transformación en áreas protegidas como es el caso de la constitución del Parque Nacional Natural Yaigojé Apaporis (9). El punto en discusión entonces es quien maneja efectivamente el territorio, porque puede que las prácticas tradicionales de explotación del territorio sean prohibidas, tal como lo denuncian varios documentos producidos por comunidades indígenas.

Otros procesos son los de reterritorialización de las comunidades campesinas, antiguamente despojadas, y que en la actualidad buscan retornar a sus tierras, volver a producir alimentos y organizarse políticamente a pesar de las amenazas persistentes $(5,14)$.

Finalmente, las amenazas pueden afectar los territorios solamente en algunos puntos estratégicos, en particular en sus límites. Tal es a situación vivida por los pueblos de la Sierra Nevada de Santa Marta que vieron amenazados los sitios sagrados ubicados en la Línea Negra (la delimitación del territorio ancestral, por fuera de los resguardos legalmente constituidos). A pesar de no tener presencia permanente en el lugar, justificaron la pertenencia del sitio sagrado de Jukulwa para impedir la construcción del puerto multipropósito de Dibulla, que finalmente se construyó luego de una concertación con ellos (10). La redefinición de los límites es un motivo de disputa frecuente, incluso en el ámbito urbano. Al respecto, son llamativas las críticas de la Mesa Interbarrial de Desconectados de Medellín contra la política de cinturón verde de la alcaldía, que frena las posibilidades de expansión informal de la ciudad y por lo tanto, dificulta el acceso a suelos urbanos baratos y encarece de manera general los precios del suelo (21).

\section{El territorio es una construcción social y política permanente}

Para los movimientos sociales colombianos estudiados, el territorio no es algo fijo, dado, sino una construcción eminentemente política, en tanto resulta de las correlaciones de fuerza del lugar y momento.

Además de la figura clásica de las áreas de conservación, los textos revisados demuestran una capacidad inventiva en cuanto a la formulación de propuestas territoriales. En su mayoría, los textos resaltan la necesaria consolidación de la toma 
de decisión desde abajo sobre el territorio: "el territorio debe construirse desde la perspectiva de la comunidad" (2). Ello implica más incidencia de los espacios de participación, la realización efectiva de consultas previas informadas pero también programas de educación y concientización. Esta dimensión ha sido muy importante en la elaboración del Plan de Desarrollo del Corregimiento Las Hermosas, un territorio percibido como históricamente marginal, con influencia de las FARC, pero en donde se logró implementar un proceso de planeación participativa. Con asesoría de ONGs y universidades, la comunidad campesina ratificó su deseo de permanencia en el territorio con un proyecto de territorio de paz y despensa alimentaria (16). Para la mayoría de las organizaciones, se trata de fortalecer la autonomía desde lo local, que también puede presentar varios rasgos (autogobierno, participación ciudadana decisoria, efectividad de los derechos territoriales y del derecho a la ciudad, etc.).

Se enfatiza en varios documentos el reconocimiento de bienes comunes, en cuanto a titulaciones colectivas de tierras como de equipamientos colectivos, servicios y recursos naturales, en particular el agua. Las propuestas concretas, que no podemos desarrollar acá, ofrecen diversas opciones para construir la autonomía territorial de las comunidades: conformación de la figura constitucional pero nunca implementada de las Entidades Territoriales Indígenas, resguardos interculturales, Zonas de Reservas Campesinas como territorios de paz donde se puede recibir e integrar guerrilleros desmovilizados, territorios agroalimentarios (22), elaboración de modelos alternativos para el territorio y promoción de la realización de Planes de Ordenamiento Territorial popular $(19,20)$.

Estos nuevos territorios son a menudo el resultado de intensas batallas jurídicas y políticas, con vaivenes durante varios años (suspensión de zonas de reservas campesinas (13), demandas contra las licencias ambientales por ejemplo de la represa El Quimbo (4), implementación de los procesos de restitución de tierras). La dimensión colectiva de estas luchas jurídicas, como en el caso de las demandas de reparaciones colectivas (14), es un asunto importante en tanto se asume el territorio como tejido de relaciones.

Así, el territorio se perfila cada vez más como un importante elemento movilizador dentro de los registros de las luchas sociales. La Cumbre Urbana y Popular adoptó el llamado sistemático al "derecho a la ciudad y al territorio" y ya no solamente "a la ciudad" (19) mientras que la Organización Nacional Indígena de Colombia transformó sus principios históricos fundadores de 1982 “Unidad, Tierra, Cultura y Autonomía" en el Congreso de 2012 en "Unidad, Territorio, Cultura y Autonomía"( 11 ). Algunos movimientos ambientales logran impulsar dinámicas de contestación de carácter masivo a escala regional, como las Marchas Carnaval en contra de la mina La Colosa donde confluyeron hasta 120000 personas en el Tolima o las consultas populares cada vez más apoyadas por los dirigentes locales y departamentales (7). Los sectores populares en Colombia siguen muy anclados territorialmente: "es un 
territorio donde el 90\% somos víctimas, pero algo muy bonito es que estamos queriendo nuestro territorio" (21).

\section{A modo de conclusión}

Las reivindicaciones de los movimientos sociales con carácter territorial se refieren a otros significados del territorio diferentes a lo que el Estado entiende por aquel. En ese sentido, es fundamental entender que en el espacio geográfico coexisten múltiples territorios. El ordenamiento territorial tradicional es solo una forma más de apropiación territorial. Estos otros significados recalcan la dimensión existencial, ontológica del territorio. Así, lo que se reivindica no es tanto el acceso a un recurso (paradigma de los comunes) sino el reconocimiento de la existencia de los grupos sociales y sus territorialidades específicas, porque la territorialidad, tanto individual como colectiva, es un elemento fundamental de la identidad. Las reivindicaciones giran en torno al derecho al territorio y a veces, se expresan jurídicamente mediante demandas por nuevas autonomías territoriales (en ese sentido, no se trata solo de un asunto de descentralización del poder sino de la posibilidad de ejercer otras territorialidades no estatales, a veces en tensión o en conflicto con la territorialidad estatal).

Es de subrayar una suerte de paradoja de lo abierto y lo cerrado: hasta ahora, el reconocimiento de los otros regímenes de territorialidad solo se da mediante el establecimiento de perímetros, zonificaciones, cuando en realidad, estos otros territorios son fundamentalmente abiertos. Nuevas formas de regulación territorial, nuevos ordenamientos territoriales, deben ser inventados para tomar en cuenta la diversidad de la multiterritorialidad y toda la complejidad con la cual se expresa concretamente: regular - porque hay que establecer mecanismos que indican lo que podemos hacer o no en ciertos lugares (no necesariamente en todos) - pero dejando abierto al reconocimiento de las multiterritorialidades que se construyen en el espacio geográfico. El registro existencial de las luchas por el derecho al territorio tiene un gran potencial movilizador para enfrentar la crisis planetaria actual ${ }^{41}$.

\section{Bibliografía}

AGNEW, John \& OSLENDER, Ulrich. “Territorialidades superpuestas, soberanía en disputa: lecciones empíricas desde América Latina". Tabula Rasa, 2010, 13: 191213.

ALLIÈS, Paul. L'invention du territoire. Grenoble: Presses Universitaires de Grenoble, 1980.

CAIRO, Heriberto, Ulrich OSLENDER, Carlo Emilio PIAZZINI SUÁREZ, Jerónimo RÍOS, Sara KOOPMAN, Vladimir MONTOYA ARANGO, Flavio Bladimir RODRÍGUEZ MUÑOZ \& Liliana ZAMBRANO QUINTERO. "Territorial Peace": The Emergence of a Concept in Colombia's Peace Negotiations, Geopolitics, 2018. DOI: 10.1080/14650045.2018.1425110

41 Latour, 2018. 
CATAIA, Márcio. “Territorialidade estatal e outras territorialidades: novas formas de uso dos territórios na América Latina. Conflitos, desafios e alternativas". Scripta Nova, 2008, 12 (270/99). http://www.ub.es/geocrit/sn/sn-270/sn-270-99.htm

COLLIGNON, Béatrice. Les Inuits, ce qu'ils savent du territoire. Paris : L'Harmattan, 1996.

ELDEN, Stuart. "Land, terrain, territory". Progress in Human Geography, 2010, 34(6): 799-817. DOI: 10.1177/0309132510362603

FAJARDO, Darío. "Experiencias y perspectivas de las Zonas de Reserva Campesina" En: Autonomias territoriales. Experiencias y desafíos, compilado por Juan Guillermo Ferro y Gabriel Tobón, 55-70. Bogotá: Observatorio de Territorios Étnicos, Pontificia Universidad Javeriana, 2012.

FALS BORDA, Orlando. Acción y espacio: Autonomías en la nueva República. Bogotá: Tercer Mundo Editores - IEPRI (UN), 2000.

FERNANDES, Bernardo Mançano. "Territorio, teoría y política”. En: Las configuraciones de los territorios rurales en el siglo XXI, editado por Fabio Lozano \& Juan Guillermo Ferro, Bogotá: Pontificia Universidad Javeriana, 2009, pp. 35-61.

FOUCAULT, Michel. Sécurité, Territoire, Population: Cours au Collège de France (19771978). Paris: Gallimard, 2004.

GIRAUT, Frédéric. "Conceptualiser le territoire". Historiens et Géographes, 2008, 403 : 57-68.

GONZÁLEZ, Miguel. “Autonomías territoriales indígenas y regímenes autonómicos (desde el Estado) en América Latina". En: La autonomía a debate: autogobierno indigena y Estado plurinacional en América Latina, coordinado por Miguel GONZÁLEZ, Araceli BURGUETE CAL Y MAYOR y Pablo ORTIZ-T. Quito : FLACSO / GTZ / IWGIA / CIESAS / UNICH, 2010.

GOTTMANN, Jean. The Significance of Territory. Charlottesville: University of Virginia Press, 1973.

HAESBAERT, Rogério. "Del mito de la desterritorialización a la multiterritorialidad". Culturas y Representaciones Sociales, 2013, 8(15): 9-42.

HERRERA ÁNGEL, Marta. Ordenar para controlar. Ordenamiento espacial y control politico en las Llanuras del Caribe y en los Andes Centrales Neogranadinos. Siglo XVIII. Bogotá: Academia Colombiana de Historia / ICANH, 2002.

HURTATIS ESPINOSA, Héctor Iván. La Asociación Campesina del Valle del Río Cimitarra como mecanismo de resistencia politica a los proyectos latifundistas en el Magdalena Medio. (2006-2010). Tesis de grado en Ciencias Políticas. Bogotá: Universidad Colegio Mayor de Nuestra Señora del Rosario, 2012.

LATOUR, Bruno. Down to Earth, Politics in the New Climatic Regime. Cambridge: Polity Press, 2018.

LEAH TEMPER, Daniela del Bene and Joan MARTINEZ-ALIER. "Mapping the frontiers and front lines of global environmental justice: the EJAtlas". Journal of Political Ecology, 2015, 22: 255-278.

LEFEBVRE, Henri. Le droit à la ville. Paris: Anthropos, 1968. 
LEFEBVRE, Henri. La production de l'espace. Paris: Anthropos, 1974.

LÉVY, Jacques y Michel LUSSAULT. “Espace”. En Dictionnaire de la géographie et de l'espace des societés, dirigido por Jacques LÉVY y Michel LUSSAULT. Paris: Belin, 2013.

MARTÍNEZ ZAMORA, Luisz Olmedo. Visiones com-partidas del territorio en un mundo dividido. El caso de la visión indígena y la del Estado. Bogotá, D.C.: Universidad Nacional de Colombia, Instituto de Estudios Ambientales, 2010.

OBSERVATORIO NACIONAL DE PAZ. Actores y dinámicas de la conflictividad territorial. Percepciones populares en cuatro regiones de Colombia. Bogotá: Planeta Paz, 2012.

PORTO-GONÇALVES, Carlos Walter. Geo-grafías: Movimientos sociales, nuevas territorialidades y sustentabilidad. México: Siglo XXI, 2001.

PORTO-GONÇALVES, Carlos Walter. "De saberes y de territorios: diversidad y emancipación a partir de la experiencia latino-americana". Polis, Revista Latinoamericana, 2009, 22. http://polis.revues.org/2636

RAFFESTIN, Claude. Pour une géographie du pouvoir. Paris: Litec, 1980.

RAFFESTIN, Claude. "Écogenèse territoriale et territorialité ", in Auriac, François \& Brunet Roger. Espaces, jeux et enjeux. Paris : Fayard et Fondation Diderot, 1986, pp.175-185.

RATZEL, Friedrich. "Le sol, la société et l'Etat". L'Année sociologique, 1898-1899, III, p.1-14. Traducción española por Josefina Gómez Mendoza en: Gómez Mendoza, Josefina, Nicolás Ortega Cantero, Julio Muñoz Jiménez. 1982. El pensamiento geográfico. Estudio interpretativo y antología de textos: de Humboldt a las tendencias radicales. Madrid: Alianza editorial.

SACK, Robert. Human territoriality. Its theory and history. Cambridge: Cambridge University Press, 1986.

SANTOS, Milton. Por uma geografia nova. Sao Paulo: Hucitec/Edusp, 1978.

SANTOS, Milton. La naturaleza del espacio. Barcelona: Ariel (trad. Española), 2000.

SAQUET, Marcos. Abordagens e concepções sobre territorio. São Paulo: Outras Expressóes, 2013.

SILVEIRA, María Laura. "Globalización y territorio usado: imperativos y solidariedades." Cuadernos del Cendes, 2008, 25(69): 2-19.

SERJE, Margarita. "Territorios y culturas: la política de territorialización indígena en la Sierra Nevada de Santa Marta". En: Ordenar los territorios. Perspectivas críticas desde América Latina. Editado por Alice Beuf y Patricia Rincón. Bogotá: Universidad Nacional de Colombia / Uniandes / IFEA, 2017.

SILVA PRADO, Diego Fernando. "Construcción de territorialidad desde las organizaciones campesinas en Colombia”. Polis, Revista Latinoamericana, 2016, 15 (43): 633-654. http://dx.doi.org/10.4067/S0718-65682016000100029.

SURRALLÉS, Alexandre. "Entre derecho y realidad: antropología y territorios indígenas amazónicos en un futuro próximo". Bulletin de l'Institut Français d'Études Andines, 2009, 38 ( 1 ):29-45. http://bifea.revues.org/2789; DOI : 10.4000/ bifea.2789 
ULLOA, Astrid. "Reconfiguraciones conceptuales, políticas y territoriales en las demandas de autonomía de los pueblos indígenas en Colombia". Tabula Rasa, 2010, 13: 73-92.

VACAFLORES, Carlos y Lizárraga Pilar. “La politización del territorio campesino. La lucha campesina por el reconocimiento en el proceso constituyente boliviano". En: Las configuraciones de los territorios rurales en el siglo XXI, editado por Fabio Lozano \& Juan Guillermo Ferro, Bogotá: Pontificia Universidad Javeriana, 2009. VACAFLORES, Carlos. "La lucha por la tierra es la lucha por el territorio". Land Research Action Network, 2009. www.landaction.org/IMG/pdf/4artigodomes/2009.pdf.

(C) Copyright: Alice Beuf, 2019

(c) Copyright: Scripta Nova, 2019.

Ficha bibliográfica:

BEUF, Alice. Los significados del territorio. Ensayo interpretativo de los discursos sobre el territorio de movimientos sociales en Colombia. Scripta Nova. Revista Electrónica de Geografía y Ciencias Sociales. Barcelona: Universidad de Barcelona, 15 de octubre de 2019, vol. XXIII, nº 624. [ISSN: 1138-9788] 